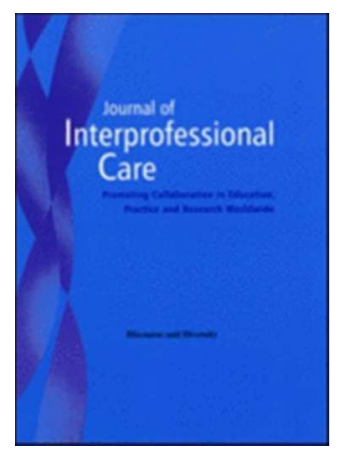

\title{
A critical narrative analysis of shared decision-making in acute, in-patient mental health care
}

\begin{tabular}{|r|l|}
\hline Journal: & Journal of Interprofessional Care \\
\hline Manuscript ID: & Draft \\
\hline Manuscript Type: & Article \\
\hline Keywords: & Focus groups, Narrative analysis, Shared decision making \\
\hline \multicolumn{2}{l}{} \\
\end{tabular}

SCHOLARONE $^{\text {I" }}$

Manuscripts 


\title{
A critical narrative analysis of shared decision-making in acute,
}

\author{
inpatient mental health care
}

\begin{abstract}
Shared decision making is a high priority in healthcare policy and is complementary to the recovery philosophy in mental health care. This agenda has been operationalised within the Values Based Practice framework which offers a theoretical and practical model to promote democratic interprofessional approaches to decision making. However, these are limited by a lack of recognition of the implications of power implicit within the mental health system.
\end{abstract}

This study considers issues of power within the context of decision making and examines to what extent decisions about patients' care on acute in-patient wards are perceived to be shared.Focus groups were conducted with 46 mental health professionals, service users and carers. The data were analysed using the framework of critical narrative analysis proposed by Langdridge (2007). The findings of the study suggested each group constructed different identity positions which placed them as inside or outside of the decision making process. This reflected their view of themselves as best placed to influence a decision on behalf of the service user. In conclusion, the discourse of VBP and SDM need to take account of how differentials of power and the positioning of speakers affect the context in which decisions take place.

Declaration of Interests

This project was funded by the Institute of Mental Health and the University of Nottingham. There is no conflict to interest to declare. 


\section{Introduction}

This article reports upon a research project examining stake-holders' perspectives on how decisions are made about individuals' care when they are patients in Adult Mental Health wards. Seven focus groups were conducted and the data were subject to a critical narrative analysis using a framework developed by Langdridge (2007).

\section{Background}

\section{Values Bases Practice}

There is a growing awareness of the need for shared decision-making (SDM) in mental health care in the UK. Values Based Practice (VBP) (Woodbridge and Fulford 2005) recognises that decisions taken in mental health care are based on values as well as the research evidence. Decision-making therefore involves incorporating the differing, and sometimes conflicting, values of those involved in planning and delivering services, service users and carers (Cleary, 2003; Colombo 2003; Fagermoen 1997). Woodbridge and Fulford (2005) highlight the range of values and their influence on SDM, advocating a "democratic" approach to interprofessional decision-making whereby the values of all involved are respected and considered. Their notion of decision-making in mental health services as a democracy is, however, not without its problems. It has been criticised as it does not adequately address issues of power and interest (Houghton and Diamond 2010). These challenges are acknowledged within the literature (Johnstone, 2000; Moncrieff, 2009; Pilgrim, 2007; Smail, 2005), although genuine SDM remains a goal.

Shared Decision Making 
The mental health service user movement and consumerist models of healthcare have significantly changed the perception of the role of the 'patient' in their own care (Ching, Aslani and Chen 2013). This shift has culminated in a policy framework that seeks to enshrine patients' choices to become the heart of future healthcare (DH 2012). The framework promotes SDM as a practice that will help to ensure people receive care that is centred on individual circumstances and choices. SDM is defined as a "... process by which clinicians and patients work together to clarify treatment, management or self-management, support goals .... with the aim of reaching mutual agreement on the best course of action" (Coulter and Collins 2011:2). Emphasis is placed on processes of understanding the person's own values and attitudes, identifying their own goals. Achieving SDM entails recognition of the person's expertise developed through the experience of health problems.

Adopting this approach to making decisions represents a departure from traditional, paternalistic models of healthcare. Within such approaches, the role of a healthcare professional is to inform the person of the options and persuade them to accept the option that the professional perceives is best for that person; whereas SDM involves sharing information, identifying the person's preferences, and jointly agreeing an option (Schauer et al 2007, Hamann et al 2011; The Health Foundation 2012 ). Making such choices about their own lives acknowledges individuals' rights, selfdetermination, autonomy and empowerment (Deegan and Drake 2006).

\section{Power}

The discourse of SDM and VBP can be criticised as one that masks differentials of power. Using a critique of ideology drawn from Marxist critical theory we could claim that the idea of SDM is a way that the dominant interests of psychiatry continue to 
ignore the wishes of the service user, by masking the reality of coercive care through an illusory discourse of interprofessional and participatory decision making (Marx and Engels, 1977). For Marx, ideologies function by covering up essential inequalities of power, through the creation of necessary illusions, that enable the system to function as though it were democratic (Eagleton, 1991). This critique of ideology demonstrates the main flaw in the VBP discourse, which presumes that differing values can be debated democratically, and fails to acknowledge the key part that differences of power and positioning play in whose voice counts (Houghton and Diamond, 2010, Smail 2005).

Whilst we believe that the critique of power is a central component of any analysis of shared decision making, following Foucault (2002), we view power as not just about a 'conflict of unequals' but as a plural concept, which both enables and constrains. Power does not repress individuals but produces subjectivities through an interplay with discourses of knowledge and truth. Who we are as individuals and the values we espouse are formed by networks of power that both enable us to take up particular identities and limit the kinds of people we are. Critique of power does not unmask an essential truth about inequalities in society, but focuses on the kinds of positions and values that are taken by individuals and institutions. Power is plural, both positive and negative, productive as well as repressive. In terms of SDM, we question the kinds of discourses and narratives that are produced in our study and how they are enabled by networks of power and conceptions of truth. There is not therefore one concept of truth in terms of a truly democratic idea of SDM; only competing truths and discourses. 
Professional subject positions are constituted by the discourses and practices that members construct in order to gain control, autonomy and dominate others. This act is associated with gaining a more privileged economic and social status (Larson 1977). Essential to this process is the acquisition and control of expert knowledge that enables the profession to construct an identity that separates it from competing occupational groups. This is often achieved through control over access to education, formalisation of knowledge through accreditation and prescription of available career paths.

\section{Research Aims}

- To examine to what extent decisions about patients' care on acute mental health wards are perceived to be shared

- Explore the extent to which participants felt their views were listened to, and contributed to the final outcome.

\section{Method}

Seven focus groups were conducted with occupational therapists, nurses, service users, carers, psychiatrists, peer-support workers and social workers. Focus groups were selected as the most appropriate means of data collection in accordance with the belief that the process of understanding social phenomena is not undertaken by individuals in isolation from each other (Blumer 1969). Rather, it is something that occurs in interaction with others and therefore focus groups offer the opportunity to explore the production of knowledge through dialogue and debate (Bryman 2001). An interview schedule was used as a guide for each of the focus groups. Groups were homogenous in relation to role. Each group was facilitated by two members of 
the research team who were mental health professionals within the fields of nursing and psychology. The focus groups were audio recorded and lasted between 45 and 90 minutes.

\begin{abstract}
A theoretical sampling strategy was adopted in order to recruit information-rich participants with the required experience to meet the objectives of the study (Denzin and Lincoln 2000). The primary criteria for recruiting participants were that attendees should have experience of inpatient care in their respective capacity or role within the last 2 years. Professionals were recruited through pre-established meeting forums within a Mental Health Trust in the UK and service-users and carers were recruited through a voluntary service user organisation. Groups were initially approached to give information about the study and offer the opportunity for potential participants to ask questions.
\end{abstract}

Table 1 - Focus Group Participants

Ethical approval was acquired through the National Health Service, National Research Ethics Service. During focus group interviews, there is the potential that confidential subjects may be spoken about. Participants were made aware not to disclose any information discussed within the focus group outside of the interview taking place. If discussions arose involving questionable practice, prevision was made for participants to be directed towards the NHS Trust complaints procedures if they wish to make a formal grievance.

Analysis

A Critical Narrative Analysis (CNA) was conducted on the data guided by the framework devised by Langdridge (2007). This form of Critical Narrative Analysis 
(CNA) combines phenomenologically informed narrative methods with a critical theory (Langdridge, 2007). As a phenomenological method, it respects individual subjectivity and takes seriously what people say (narratives) about their experiences. As a critical method, it uses political critique to question people's narratives, taking the position that people always speak from somewhere, from some tradition and some ideological position. Rather than seeing these positions as incompatible or mutually exclusive, CNA sees phenomenology and critical theory as mutually informing. Thus, adopting this form of analysis allowed us to explore both how our participants experience decision-making processes and how issues of power and interest are at play in those processes.

Davies and Harré (1990) drew attention to dynamic aspects of interaction through the concept of 'positioning'. 'Positioning' is largely a conversational phenomenon. During the course of a conversation the participants "make (or attempt to make) their own and each other's actions socially determinate" (Davies \& Harré, 1990, p. 45). Multiple speech acts may be accomplished by any single utterance. 'Positioning' is one of these speech-acts and occurs constantly in the flow of social interactions; including research focus groups.

Using discourse and talk, speakers rhetorically construct themselves and others in specific ways (Billig, 1987). Here, "a discourse is to be understood as an institutionalised use of language" (Davies \& Harré, 1990, p. 45). Discourses are forceful because they provide (and constrain) subject positions, which locate people (and their rights and responsibilities) within the discourse and affect which social actions are possible (Davies \& Harré, 1990). Particular subject positions allow the speaker the "right to be taken seriously or to be granted superiority" (Gergen, 1989, 
p. 74). That is, the subject position gives the speaker a 'warranting voice': the right to say certain things because they either have specialist knowledge or are granted particular powers. Specialist knowledge might be to do with empirical matters or with specialist training.

The analysis involved six stages including; 1) a critique of the illusions of subjectivity, 2) narrative tone and function; 3) identities and identity work; 4) thematic priorities and relationships. Stages $1-4$ were completed by the members of the research team who conducted the focus group for each group individually. These interpretations were discussed within the wider research group during a series of analysis workshops which focused on stages 5 to 6 facilitating an in-depth consideration of patterns and differences across the groups. These workshops were facilitated by an external person with specific expertise in the analytical framework. The research team consisted of individuals with professional backgrounds in nursing, social work and psychology. This analytical process enabled researchers to challenge, question and justify interpretations which highlighted the importance of stage one. In this stage researchers reflected on their value position in relation to the focus of the study and their expectations. This collaborative reflexive approach strengthened the rigor of interpretations.

The themes of power, human relationships, and the systems of decision making in mental health services were prevalent in the data. This paper will focus on stages 5 and 6 which involved destabilising (or questioning) the narratives by engaging directly in a political critique of the text. A summary of the key positions, the warranting voices and implications of power is presented in Table 2 and discussed in the following section. Stage 6 identified the various subject positions which needed 
not be formal or officially recognised roles (e.g. occupational therapist, parent, etc.) Rather, they could be informal and dynamic (e.g. 'victim', 'outsider'). The findings will be presented discursively with examples of how interpretation were expressed within the data.

Discussion of Findings

Participants in all focus groups except psychiatrists, consistently positioned themselves as being outside the decision making systems. Being outside this system was influenced by alignment with services users or a lack of perceived professional status. For example occupational therapists often positioned themselves as outside of the decision-making system, strongly aligning themselves with service users. This created an 'us' versus 'them' scenario, with occupational therapists and service users on one side and all other professions on the other. This was a way of saying that they are on the side of the service users and, by implication, they too, have no power.

We fit with the patient, don't we? Because we're usually fighting for the patient. We're fighting for what their wants and needs are in terms of recovery, in terms of how they want to spend their life. So often, we come a bit left of centre really

Peer support workers also positioned themselves as outside the decision-making process. There was a tension between the identity of peer support worker and that of 'patient'. Having experienced being a 'patient' they strongly identified with the service users they support, distancing themselves from the machinery of the institution. But, as paid peer support workers they undoubtedly are part of the system. 
“Yes, we'll advocate for a patient, we'll be a peer support worker, but as potential participants in a review, we're putting ourselves at a sort of a risk, I don't mean at a personal risk but I mean, is it possible that a patient, oh a service user, would then begin to think actually, are they a part of the system?"

Additionally one carer spoke of themselves as being an outsider due to being 'in the way':

I was considered to be a nuisance. When they opened the doors for me to go into the ward where my son was, I was in the way, literally and figuratively, I was a bit of a nuisance so I was pushed up into one corner, and I would be told when I could go through and see my son.

This can be seen as the carer positioning themselves as outsiders to rhetorically elicit sympathy or to point the finger of blame. But, equally this can be taken to be evidence that it is the mental health system that positions carers as outsiders. The choice is not either/or, rather both situations are simultaneously plausibly valid. That is, the system may well position carers outside of its processes and carers subsequently take up the subject position of powerless to influence the system.

Social workers, too, positioned themselves as outsiders, distancing themselves from the ward environment and from ideologies and processes that they do not agree with. This positioning gives social workers a way of disclaiming responsibility for the difficult decisions of inpatient settings. Social workers spoke of feeling like they only had influence when occupying the professional position of Approved Mental Health Practitioner (AMHP). They said they were clear about their responsibilities and status as AMHPs and that the medical system is dependent on them within that role: 
I think it's much easier being in an (AMHP) role. It feels as if there's more equality between people that are making that decision, really. I feel that that's the best part of me being a social worker, in terms of that level of equality with the medics. And, really, feeling that I've got a voice and the authority to say what I feel about a situation

This suggests that the AMHP role is a liminal position as it it brings outsiders inside. In this way, the role of AMHP gives social workers a warranting voice in the decisionmaking process. But, since it is explicitly written as a non-medical role, social workers are also given permission to criticise the medical system.

Service users however position themselves as subject to the system. The grand narrative that was presented was one of disempowerment. This was poignantly illustrated by all participants in this focus group relating their experiences of having their freedom, choices and rights removed against their will. What was apparent though was that it was not necessarily having their freedoms curtailed that disempowered them, but the manner in which they were treated. Participants were aware that at times they needed to be "looked after"; they recognised that at times they were unable to take full control and responsibility for themselves.

I think the structure (ward review) is ridiculous and frightening. Because all the people on that end, and there's one chair where we sit, like, you're out in a space on your own... You're not in that circle. You're the odd one out in other words.

In this critical moment when decisions are being made, the service users felt 'outsiders' as well as being at the bottom of the hierarchy. 
Psychiatrists talked about having most responsibility for decisions. For them, responsibly meant making the decision as opposed facilitating shard decision making. This suggests that in this context 'responsibility' is just another word for power. However, this position was balanced by recognition of how psychiatrists were viewed by their peers in the medical profession. When it came to the process of shared decision making, the psychiatrists spoke of their position with an air of resigned paternalism:

.... I still feel responsible if I hadn't overseen it, but then, you haven't the ability to oversee everything so you have to give them responsibility and the accountability but at the same time, something goes wrong, you still know you're going to get it in the neck at the end of the day, but I think you just have to accept that, and I think it's a matter of trust really. If you can trust the people you work with to do a good job, you know, or a reasonable job, then, I think you're kind of half way there really.

There was a consistent view of the need to guide others and to ensure that decisions were implemented. Members of this group spoke of how they attempted to include others, but revealed that they were skeptical of other professional's willingness to take responsibility.

It was apparent that, within decision-making, psychiatrists are perceived by all other groups as at the top of the hierarchy, holding most power, rights and responsibilities. Supporting this, Nurses presented an image of their role as a functionary. This position of the nurse entails the facilitation of processes, ensuring that the ward operates smoothly and decisions made by doctors are carried out and followed through: 
....you facilitate what has been decided and you are co-ordinating as well, because very often, a lot of those decisions are going to involve community services or other agencies, so you're going to take that away from your MDT and that is your responsibility and the team's responsibility to put into practice.

Nurses spoke in terms of waiting for decisions to be made by physicians before implementing them. In many cases this means that nurses are enforcers of surveillance, restraint, isolation, and medication of service users. This group spoke of enforcement as horrible but necessary, coming at some personal cost to the nurse. When talking about coercion, nurses often used the collective pronoun 'we'. This can be interpreted in at least two ways. First, it expresses a strong identity of being part of a team and an acceptance of collective responsibility. Secondly, though, the use of 'we' depersonalises the coercive practice, distancing the individual nurse from the activity.

Discussion - Who knows best?

A strong discourse of influence and interest was evidently present in the data. All groups, while nominally talking about the interests of service users, also spoke about their own interests. This often involved the linguistic construction of boundaries or identities for their group in terms of their role in the system, including what rights and responsibilities they have or do not have. The 'who knows best?' argument is a device used to gain influence and maintain interests (Gergen 1989). Whoever successfully positions themselves as having superior knowledge becomes the group with the most influence. At present, psychiatrists successfully use their medical training and social status to position themselves as the most knowledgeable group and thus have most influence in acute mental health care. Therefore goal of shared 
decision making in acute settings is a long way from being met. All focus groups felt that decisions were not shared and that the voice of the service user was marginalised.

Questioning this further however reveals how the findings of this study demonstrate how each group involved in decision making absolved themselves of the capacity to take on the responsibility of making decisions. Whilst they were critical of the hierarchical nature of decision making processes this functioned to maintain the current power relationships. Decisions made in mental health care can involve restriction of liberty and enforced treatment. It was evident that most groups would rather distance themselves from decisions that meant personal freedom was revoked to avoid being viewed as at blame.

The discourse of VBP and SDM need to take account of how differentials of power, interests and the positioning of speakers affect the process of how decisions take place. The power critique which conceptualizes SDM as an illusion (Eagleton, 1991) has been challenged by the findings of this study as all groups agreed that there is a decision making hierarchy. The literature discussing SDM in a range contexts focuses on putting the service user at the center of decision making processes however our findings show that this is currently political rhetoric as warned by The Health Foundation (2012).

Conclusion

This study has presented a critical narrative analysis of multiple perspectives of how decisions are made about patient care. There is recognition amongst all parties that the system does not facilitate decision-making that is genuinely shared. Each of the groups has their respective values but they each position themselves relatively 
powerless to change the system to make shared decision-making authentic.

However, very real power hierarchies exist and have powerful effects on actors within the hierarchy. This suggests that the current structures may at best obscure and at worst actively obstruct new ways of working. Whilst it is important for professional groups to maintain their professional identities in healthcare settings, they might also need to consider the need to talk about their identities in groups and with other groups and acknowledge uncertainties of role. Until the role and identity of the professional groups is understood in the context of power, a practical implementation of shared decision-making will be illusory. By creating space for open debate there could be potential for the service user to be valued in terms of their expertise. 


\section{References}

Billig, M. (1987). Arguing and thinking: A rhetorical approach to social psychology. Cambridge: Cambridge Univ Billig,ersity Press

Blumer H. (1969) Symbolic Interactionism: Perspectives and Method. University of California, Berkeley and Los Angeles.

Bryman A. (2001) Social Research Methods. Oxford University Press, Oxford.

Cleary, M., (2003) The challenges of mental health care reform for contemporary mental health nursing practice: Relationships, power and control. International Journal of Mental Health Nursing. 12 pp.139-147

Colombo, A (2003) Evaluating the influence of implicit models of mental disorder on the process of shared decision-making within community-based multi-disciplinary teams. Social Science and Medicine 56(7) pp.1557-1570.

Coulter A, Collins A (2011) Making Shared decision making a reality, No decision about me, without me. London Kings Fund.

Davies, B. \& Harré, R. (1990). Positioning: The discursive production of selves. Journal for the Theory of Social Behaviour, 20(1), 43-63

Deegan P, Drake R(2006) Shared Decision Making and Medication Management in the Recovery Process. Psychiatric Services 57(11) 1636-1639

Department of Health (2012) No decision about me without me: Liberating the NHS. HMSO.London

Eagleton, T (1991) Ideology. An Introduction, London: Verso. 
Foucault, M (2002) Archaeology of Knowledge. Routledge, New York

Freidson, E. (2001) Professionalism, the Third Logic. University of Chicago Press, Chicago

Gergen, K.J. (1989). Warranting voice and the elaboration of the self. In J. Shotter \& K.G. Gergen (Eds.), Texts of identity (pp.70-81). London: SAGE

Hamann, J Mendel, R, Buhner M, Kissling W, Cohen R, Knipfer E, Eckstein HH (2011) How should patients behave to facilitate shared decision making-the doctors' view. Health Expectations 15 360-366

Houghton, P. and Diamond, R. (2010) 'Values-based practice: a critique', Clinical Psychology Forum, 205: 24-7.

Langdridge, D. (2007). Phenomenological Psychology: Theory, Research and Method. Harlow: Pearson Education.

Larson, M.S. (1977) The Rise of Professionalism: A Sociological Analysis University of California Press. California

Marx K and Engels F (1977) The German Ideology, edited with an introduction by C.J. Arthur, London: Lawrence and Wishart.

National Institute for Health and Care Excellence (2009) Clinical Guidelines and Evidence Review for Medicines Adherence: Involving Patients in decisions about prescribed medicines and supporting adherence London. National Collaborating Centre for Primary Care and Royal College of General Practitioners. 
Schauer C, Everett A, del Vecchio P, Anderson L (2007) Promoting the Value and Practice of Shared Decision-Making in Mental Health Care Psychiatric Rehabilitation Journal 31(1) 54-61

Smail, D. (2005) Power, Interest \& Psychology, Ross-on-Wye, PCCS books.

The Health Foundation (2012) Helping people share decision making: A review of evidence considering whether shared decision making is worthwhile. The Health Foundation: London

Woodbridge, K. \& Fullford, B. (2005) Whose Values? A workbook for values-based practice in mental health care. SCMH, London 
1

2

Table 1 - Focus group participants

\begin{tabular}{|l|l|}
\hline Group & No. of participants \\
\hline Service users & 5 \\
\hline Carers & 6 \\
\hline Occupational therapists & 8 \\
\hline Psychiatrist & 6 \\
\hline Nurses & 7 \\
\hline Peer support workers & 5 \\
\hline Social workers & 9 \\
\hline
\end{tabular}


Table 2 - Summary of Findings

\begin{tabular}{|c|c|c|c|}
\hline Group & $\begin{array}{l}\text { Summary of how groups positioned } \\
\text { themselves within shared decision } \\
\text { making }\end{array}$ & $\begin{array}{l}\text { Who knows best for } \\
\text { the service user? (the } \\
\text { warranting voice) }\end{array}$ & $\begin{array}{l}\text { Impact of power on narratives } \\
\text { (destabilisation) }\end{array}$ \\
\hline Service Users & $\begin{array}{l}\text { Coerced but at times need to be } \\
\text { 'looked after' }\end{array}$ & $\begin{array}{l}\text { Sometimes it is us, } \\
\text { sometimes we don't } \\
\text { know what is best }\end{array}$ & $\begin{array}{l}\text { Might be times that decisions } \\
\text { need to be made for service } \\
\text { users. }\end{array}$ \\
\hline Carers & $\begin{array}{l}\text { Felt no place in decision making } \\
\text { Professionals/systems purposefully } \\
\text { excluding }\end{array}$ & $\begin{array}{l}\text { We would know best } \\
\text { because we are closest } \\
\text { to the person }\end{array}$ & $\begin{array}{l}\text { There is a conflict between } \\
\text { parental role and autonomy of } \\
\text { service user. }\end{array}$ \\
\hline Peer Support & $\begin{array}{l}\text { No voice in decision making } \\
\text { Tension no right/power to be part of } \\
\text { decision } \\
\text { Shared helplessness }\end{array}$ & $\begin{array}{l}\text { Claim for particular } \\
\text { knowledge based on our } \\
\text { expertise by experience. } \\
\text { The service user } \\
\text { themselves knows best, } \\
\text { we don't have a right to } \\
\text { make decisions for } \\
\text { them. }\end{array}$ & $\begin{array}{l}\text { They are positioned within a } \\
\text { network of power but } \\
\text { disclaiming any rights to } \\
\text { contribute they will never have } \\
\text { influence. However, they are at } \\
\text { the bottom of the professional } \\
\text { power hierarchy. }\end{array}$ \\
\hline Social Workers & $\begin{array}{l}\text { AMP provides vehicle for being } \\
\text { respected in shared decisions } \\
\text { Not part of the ward process coming } \\
\text { from outside }\end{array}$ & $\begin{array}{l}\text { Law and experience } \\
\text { legitimises our role in } \\
\text { decision making }\end{array}$ & $\begin{array}{l}\text { Distancing themselves from } \\
\text { ward environment enables } \\
\text { disclaiming of responsibility }\end{array}$ \\
\hline
\end{tabular}




\begin{tabular}{|l|l|l|l|}
\hline Psychiatrists & Expected to make decisions & $\begin{array}{l}\text { We know best due to } \\
\text { our role, status } \\
\text { education and } \\
\text { expectations. We feel } \\
\text { that they were the } \\
\text { leaders for better or } \\
\text { worse. }\end{array}$ & $\begin{array}{l}\text { Paternalistic tone represents } \\
\text { position of power }\end{array}$ \\
\hline Nurses & $\begin{array}{ll}\text { Enforcers of decisions } \\
\text { Ounctionary, Facilitator, Collective } \\
\text { voice }\end{array}$ & $\begin{array}{l}\text { We spend more time } \\
\text { with service users than } \\
\text { anybody else. }\end{array}$ & $\begin{array}{l}\text { Collective pronoun function to } \\
\text { distance responsibility }\end{array}$ \\
\hline Occupational Therapists & $\begin{array}{l}\text { Aligned with service user limits power } \\
\text { in decisions } \\
\text { Clear about expertise but outnumbered } \\
\text { and side-lined } \\
\text { Built alliances to promote influence }\end{array}$ & $\begin{array}{l}\text { We know best how to } \\
\text { assess people and help } \\
\text { them recover. }\end{array}$ & $\begin{array}{l}\text { Imply no power as aligned to } \\
\text { service users but this disclaims } \\
\text { responsibility }\end{array}$ \\
\hline
\end{tabular}

